\title{
Inland Electronic Navigation Chart production at the Flemish Hydrography (Flanders - Belgium)
}

\section{Dumollin Jasmine, Belgium}

Flemish Ministry of Mobility and Public Works, Agency for Maritime and Coastal Services, Flemish Hydrography, Vrijhavenstraat 3, 8400 Ostend, Belgium

Charles de Jongh, The Netherlands

Cartographic \& GIS Specialist, CARIS BV, Heeswijk, The Netherlands

Topic: K Hydrography in the Benelux

\section{INTRODUCTION}

Safety of navigation on inland waterways is as important as in maritime waters. To guarantee the latter, Electronic Navigational Charts (ENCS) have been produced since several years.

As inland waterways have specific features and specific regulations different from the maritime area, the use of existing ENCs is not sufficient. Therefore international standards have been developed specifically for Inland ENCs. They contain all chart information required for safe navigation on inland waterways and in mixed traffic zones, where both maritime and inland vessels navigate.

The Flemish Hydrography is producing these Inland ENCs, on the authority of several commissioning bodies such as the Shipping Assistance Division of the Agency for Maritime and Coastal Services and the Ports of Ghent, Zeebrugge and Ostend.

These navigational charts are extremely important as they cover not only the maritime navigation zone, but also the adjacent inland waterways which haven't been mapped before on nautical charts.

This article is looking in more detail why and how the Inland ENCs are produced and used.

\section{LEGAL REGULATIONS OF EUROPEAN INLAND WATERWAYS}

As opposed to maritime navigation, which is governed by the worldwide regulations of the International Maritime Organisation (IMO), the navigation on inland waterways is regionally regulated. In Europe it is regulated by the European Code for Inland Waterways (CEVNI) of the United Nations.

In order to support inland waterway transport the European Directive 2005/44/EC of 7 September 2005, also known as the RIS Directive, establishes a framework for the development and use of harmonised River Information Services (RIS). This Directive provides a framework for the establishment and further development of technical requirements, specifications and conditions to ensure harmonised, interoperable, and open RIS on the Community inland waterways.

The same Directive obliges authorities to make official charts available for waterways of class Va (UNECE, 1998) and above, including the ports on such waterways. The commissioning bodies provide all the data that are to be charted by the Flemish Hydrography.

\section{DEFINITION AND CONTENT OF INLAND ENCS}

A detailed definition of Inland ENC has been elaborated by the Inland ENC Harmonization Group (IEHG, 2007):

'The database, standardized as to content, structure and format, for use with inland electronic chart display and / or information systems operated on board of vessels transiting inland waterways. 
An IENC is issued by or on the authority of a competent government agency, and conforms to standards initially developed by the International Hydrographic Organization (IHO) and refined by the Inland ENC Harmonization Group.

An IENC contains all the chart information necessary for safe navigation on inland waterways and may contain supplementary information in addition to that contained in the paper chart (e.g. sailing directions, machine-readable operating schedules, etc.) which may be considered necessary for safe navigation and voyage planning. [IENC Encoding Guide, Edition 2.2, Feb 2010]'

Inland ENCs have to cover the specific features of the inland waterways. They are also produced for the so-called mixed traffic zones in which not only inland navigation but also maritime navigation happens. In Flanders the channel Ghent-Terneuzen and the Scheldt are defined as such mixed traffic zones. Inland ENCs contain a lot more details about bridges and locks for instance, than a maritime ENC. Buoys, traffic signs and other features that are specific to inland navigation are also charted.

Inland ENCs are based on an approach which is very similar to S-100 (IHO, 2010):

- The S-57 (IHO,2000) object classes, attributes and attribute values are used as far as possible;

- Introduction of new combinations of existing elements, if necessary;

- Introduction of new object classes, features or enumerations if necessary.

To ensure a common understanding and the same encoding in different areas, a very detailed Encoding Guide for Inland ENCS (IEHG, 2011(b)) has been established. This guide replaces the section "Use of the Object Catalogue" of S-57.

Inland ENCs are compiled for a variety of navigational purposes, the so-called usages. For maritime ENCs S-57 defines 6 usages: Overview, General, Coastal, Approach, Harbour and Berthing. On top of these 4 additional usages specifically related to Inland ENCs have been defined: River, River harbour, River berthing and Overlay.

Inland ENCs are displayed on board ships using an Inland ECDIS system. This is the version of the Electronic Chart and Display Information System that is used for inland navigation to read maritime ENCs.

\section{OVERVIEW OF COMPILED INLAND ENCS}

Since 2010 Flemish Hydrography produces Inland ENCs. As the already existing production of maritime ENCs with the CARIS HPD software met the requirements, it was obvious to choose the same software and database. After a succesfull test period an integrated system for all existing chart products within the Flanders Hydrography has been established. The Inland charts are produced on the authority of the Shipping Assistance Division of the Agency for Maritime and Coastal Services and on the authority of the Ports of Ghent, Zeebrugge and Ostend.

The Flemish Hydrography is using the Inland ECDIS Standard 2.3 (IEHG, 2011(a)). This Standard consists of:

- Edition 2.3.4. of the Encoding Guide (IEHG, 2011(b);

- Edition 2.3. of the Product Specification for Inland ENCs (IEHG, 2011(c));

- Edition 2.3 of the Inland ENC Feature Catalogue (IEHG, 2011(d))

The total area that has been charted is approximately $640 \mathrm{~km}^{2}$. This area is divided into 7 separate Inland ENCs to be able to comply with the maximum recommended size of each individual cell of 5MB (see Figure 1). These are:

- Inland ENC Channel Ghent - Terneuzen adjacent to the seaport of Ghent (1);

- Estuarian navigation (5-miles zone Belgian Continental Shelf) including seaport Zeebrugge (2);

- Channel Boudewijn: connecting outport Zeebrugge with the inner harbour Bruges (3);

- Antwerp N: western Scheldt from Dutch-Belgian border to Antwerp Rede (4); 
- Antwerp S: Antwerp Rede to lock of Wintam (5);

- Estuarian navigation (5-miles zone Belgian Continental Shelf) including seaport Ostend(6);

- Channel Plassendale: locks outport Ostend till lock Plassendale (7).

All compiled Inland ENCs are on usage 7, meaning 'Navigating the inland waterways'. The Flemish Hydrography uses a compilation scale of $1 / 10000$.

The working area of the Flemish Hydrography is shown in Figure 1.

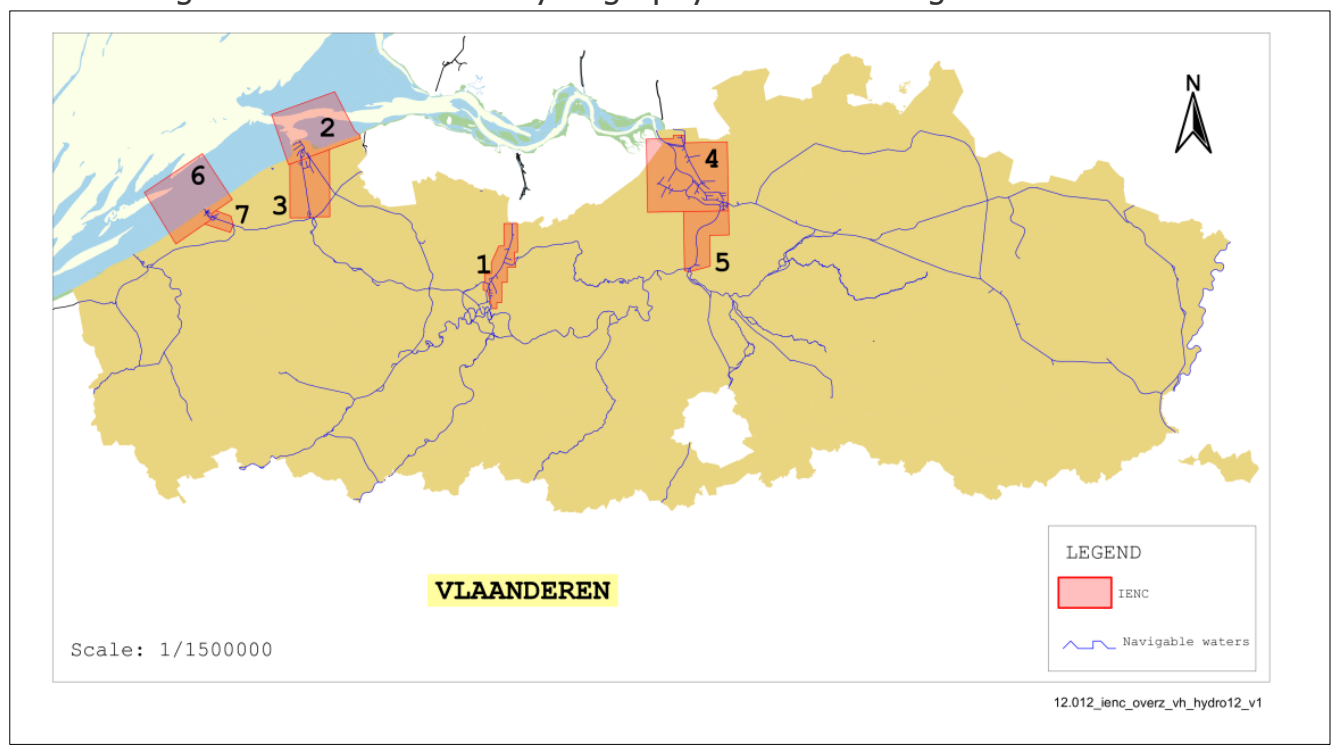

Figure 1: Inland ENCs produced by the Flemish Hydrography

The Flemish Hydrography is currently authorised to produce above mentioned Inland ENCs. The compilation of the Inland ENCs of the remaining Inland Waters in Flanders (approximately 1000 running $\mathrm{km}$ ) is done by the 2 main Waterway Authorities 'Waterwegen and Zeekanaal $\mathrm{NV}^{\prime}$ and 'NV De Scheepvaart'.

As an example a detail of the Inland ENC Channel Ghent-Terneuzen is shown below in figure 2. The mapped area of the entire Inland ENC is approximately $56 \mathrm{~km}^{2}$. One of the most important objects to be mapped on this channel is the bridge at Zelzate. A lot of metadata is linked to this object. The detail below shows the information concerning the 'Communication Area' which is defined nearby this bridge. At the left bottom (inspector window) the additional information is shown. 


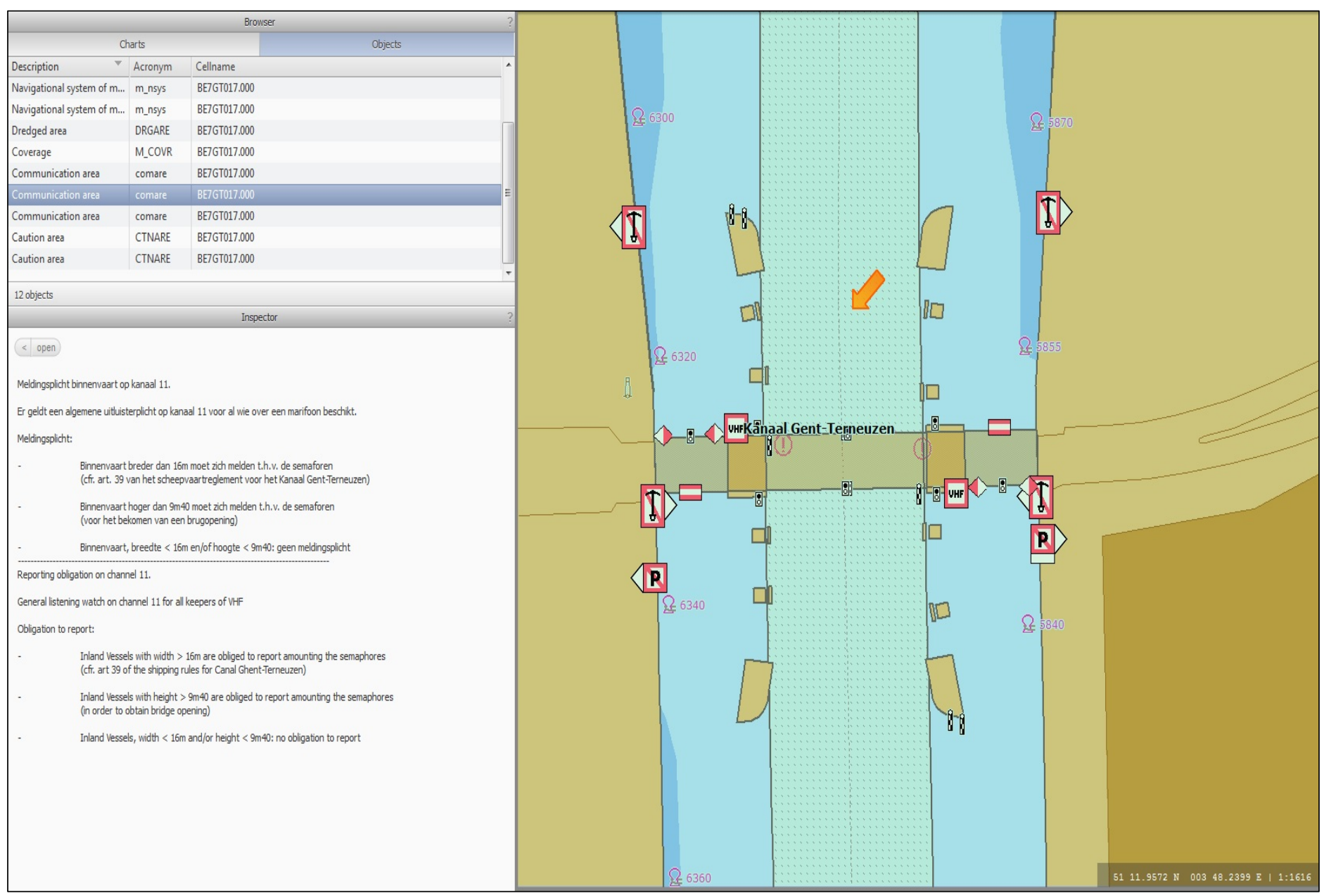

Figure 2: detail of the Inland ENC Channel Ghent-Terneuzen

\section{COMPILATION WORKFLOW}

At the Flemish Hydrography the data on Inland ENCs comes from different sources. The bathymetry is coming from surveys that are stored and managed in a gridded format in the CARIS Bathy Database Suite. The bathymetry is exported from there in an S- 57 vector format. The same bathymetry is used on ENCs, Inland ENCs and paper charts (depending on the scale of the data).

The (maritime) infrastructure that is shown on nautical products is coming from waterway authorities, shipping assistance, maritime access, harbours and others. Data is usually delivered in the form of ESRI Shape or AutoCAD vector formats and imported in the CARIS Hydrographic Production Database (HPD) where it's stored in an S-57 vector format and combined with the bathymetry.

HPD is a database driven solution, based upon Oracle, that consists of different components. In the HPD Source Editor all hydrographic vector information is stored, managed, validated and verified. The data is stored on different so called usages, corresponding to different generalization levels of the cartographic products.

Verified data is used in the HPD Product Editor, for the creation of ENCs and Inland ENCs. The Paper Chart Editor, which is another component of HPD, is used for the creation of INT1 nautical charts. All these products are produced from the same source database. This allows the use of one feature on multiple products, which increases efficiency. 
Like ENCs, Inland ENCs are exported in S-57 format and put into a so called Exchange Set. After an external quality control using software of TRESCO, SevenCs and Periskal, the Inland ENCs are placed on the River Information Services Portal from which they can be downloaded to be used on board ships.

Figure 3 shows in detail the Inland ENC production workflow within the Flemish Hydrography.

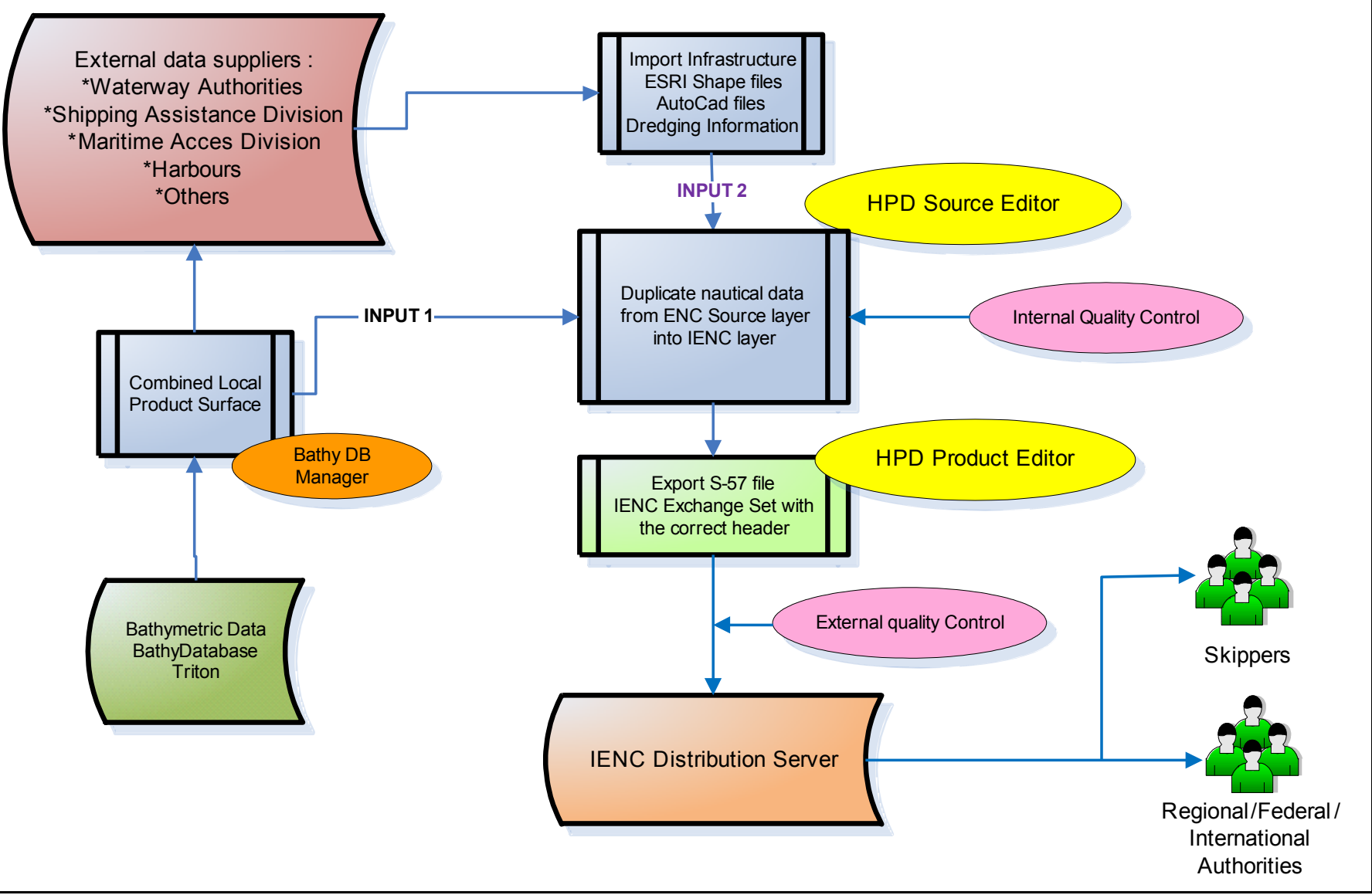

Figure 3: Inland ENC workflow production

\section{AVAILABILITY AND USE}

The Inland ENCs are intended for any inland vessels that travel in the areas shown in figure 1 and have an Inland ECDIS system on board. The Inland ENCs are free of charge and can be downloaded in a client friendly way through the Flemish RIS portal (RIS Flanders, 2008).

Additionally the charts made on the authority of the ports can be downloaded through their own websites.

\section{CONCLUSION}

The Flemish Hydrography has been able to set up an efficient Inland ENC Production unit in parallel to the other existing hydrographical production units within the team. The choice of the software CARIS HPD for the compilation of the Inland ENCs totally met the expectations. 


\section{REFERENCES}

UNECE, 1998. Inventory of Main Standards and Parameters of the E Waterway Network.

http://www.unece.org/fileadmin/DAM/trans/doc/finaldocs/sc3/ECE-TRANS-SC3-144r1e.pdf.

IEHG, 2007. Inland ENC Harmonization Group. http://ienc.openecdis.org.

IHO, 2010. " S-100 Universal Hydrographic Data Model." 1.0.0th edition, accessed January 2010. http://www.iho.int/iho_pubs/IHO_Download.htm.

IHO, 2000." S-57 IHO Transfer Standard for Digital Hydrographic data." 3.1th edition, accessed November 2000. http://www.iho.int/iho_pubs/standard/S-57Ed3.1/31Main.pdf.

IEHG, 2011(a). Inland ECDIS Standard 2.3. Draft. http://ienc.openecdis.org/?q=node/34.

IEHG, 2011(b). "Encoding Guide for Inland ENCs." 2.3.4th edition, accessed June 2011. http://ienc.openecdis.org/files/Inland_ENC_Encoding_Guide_Edition_2_3_4.pdf.

IEHG, 2011(c). Product Specification for Inland ENCs. " Product Specification for Inland ENCs." 2.3th edition, accessed January 2011. http://ienc.openecdis.org/files/ProdSpec_IENC_2_3.pdf.

IEHG, 2011(d). Inland Feature Catalogue. "IENC Feature Catalogue." 2.3th edition, accessed June 2011. http://ienc.openecdis.org/files/IENC_FC_23.pdf.

RIS Flanders, 2008. River Information Services Portal Flanders. http://ris.vlaanderen.be.

CONTACT DETAILS (of corresponding author only)

DUMOLLIN JASMINE

Flemish Ministry of Mobility and Public Works, Agency for Maritime and Coastal Services, Flemish Hydrography

Vrijhavenstraat 3

8400 Ostend

BELGIUM

Tel.: +32 (0)59554 252

Fax: +32 (0)59 507037

Email:jasmine.dumollin@mow.vlaanderen.be

www.vlaamsehydrografie.be 